\title{
SABERES E PODERES: PROPOSIÇÕES E PROVOCAÇÕES A PARTIR DA INFÂNCIA, DA ESCOLA E DA FORMAÇÃO DOCENTE
}

\author{
César Donizetti Pereira Leite*
}

\begin{abstract}
RESUMO
O tema "Infância, Escola e Formação Docente", sugere uma infinidade de percursos, caminhos e sendas pelos quais podemos circular. Este texto indicará a possibilidade de andar nos descaminhos das tramas e dos enredos que constituem as idéias de Educação e de Escola, bem como de Infância e de Formação Docente. Para tanto, partiremos de uma concepção etimológica de 'disciplina', procurando pensar este conceito naquilo que o define enquanto um campo de 'saber' e de 'poder', para então apontar uma reflexão sobre as possibilidades de um saber a respeito da Educação. Buscaremos no cinema, na literatura e nas artes plásticas possibilidades que indiquem estas tramas de sentidos no campo das práticas educativas.
\end{abstract}

PALAVRAS-CHAVES: Educação. Escola. Infância e Formação Docente.

\begin{abstract}
The subject "Infancy, School and Teaching Formation", it suggests a infinity of passages, ways and footpaths for which we can circulate, this text will indicate the possibility of walking in the
\end{abstract}

Doutor em Educação e professor do Departamento de Educação do Instituto de Biociências da UNESP- Rio Claro. 
embezzlements of the trams and the story that constitutes the ideas of Education and School, as well as of Infancy and Teaching Formation. For in such a way we will leave of a etymologic conception of 'disciplines' looking for to think this concept about what it defines it while a field of 'to know' and 'to be able', for then pointing a reflection on the possibilities of one to know on the Education. We will search in the cinema, in literature and the plastic arts possibilities that indicate these trams of sensible in the field of practical the educative ones.

KEYWORDS: Education. School. Infancy. Teaching Formation.

\section{Pontos de partida}

O tema "Infância, Escola e Formação Docente" sugere uma infinidade de percursos, caminhos e sendas pelos quais podemos circular. Optar pelo mais curto nem sempre significa percorrer o mais seguro, nem tão pouco fazer supostamente o mais fácil é garantia de caminhar com mais tranqüilidade. Decidi correr um risco, o de andar nos descaminhos das tramas e dos enredos que constituem as idéias de Educação e de Escola, bem como de Infância e de Formação Docente.

Os tecidos destes fios me colocam diante da necessidade de criar um recorte, que se funda naquilo que é determinante na idéia de Educação, a questão da "infância". Para tal indicarei uma esclarecedora citação de Gagnebin (1997, p. 84)

[...] a reflexão filosófica e a reflexão pedagógica nascem juntas, porque é em redor da questão da Paidéia que se constitui o primeiro 'sistema' filosófico, o pensamento de Platão [...]. O espírito do homem não lhe és um dado, de maneira completa e de deve ser reforçado. $\mathrm{O}$ monstro dos filósofos é a infância. Ela também é sua cúmplice. A infância lhes diz que o espírito não é (um) dado. Mas um possível.

Educ. e Filos., Uberlândia, v. 21, n. 41, p. 155-167, jan./jun. 2007. 
É aqui que pauto meu argumento. De que só falamos em Educação se também podemos falar neste 'vir a ser' do in-fans, e aqui que pego o gancho para dizer que falar do devir na infância é falar do percurso de transformação destes seres que ainda "não são", porque não falam, não possuem razão, e nem linguagem, em seres de palavra, de linguagem.

Este percurso que na modernidade se tornou sinônimo de construção de lógica e de verdades científicas foi ganhando os espaços das reflexões entorno não só da educação de um modo geral, mas também e, sobretudo, da educação escolar, se confundindo com os currículos escolares que pautam os modos de organização da escola e de orientação do trabalho do professor.

É neste sentido que, passo primeiro a discutir a escola e a educação para em um segundo momento refletir sobre a formação docente.

\section{Educação e Escola}

Definirei, grosso modo, educação como todo processo em que seres humanos se relacionam, e que neste relacionar-se se 'fazem', se 'formam' e se 'transformam'. Desta forma, educação pressupõe um espaço de relações humanas onde palavras, sentidos, afetos, corpos e pessoas se posicionam, marcam lugares, definem ações e se encontram. Neste sentido, nos educamos nas escolas, nas famílias, nas ruas, nos bares, nas Igrejas, no cotidiano. A educação em nossa cultura ocidental, moderna, acabou por se institucionalizar e ganhar os contornos dos muros das escolas e de nossas casas.

É neste aspecto que retorno Foucault que em A Ordem do Discurso é contundente, ao nos perguntar:

O que é, afinal, um sistema de ensino senão a ritualização da palavra, senão uma qualificação e uma fixação dos papéis dos sujeitos que falam, senão a constituição de um grupo doutrinário ao menos difuso, senão a distribuição e uma apropriação do discurso com seus poderes e seus saberes? (FOUCAULT, 1999, p. 44-45). 
Foucault nos questiona, mas também abre perspectiva para pensarmos sobre suas colocações. Ao apontar, indicar estas perspectivas, ele nos encaminha para suas reflexões sobre a idéia de disciplina.

Pensar etimologicamente este termo poderia nos colocar diante de uma variedade de possibilidades, farei apenas um destes movimentos. 'Disciplina' segundo o Glossário etimológico de termos usuais na prática docente de Costello e Márcico (apud Kohan, 2002) está certamente ligada ao verbo discere, que significa aprender. É daí também que se deriva palavra como discipulus (quem aprende), o aluno - o aprendiz - o discípulo. Em seus primeiros usos disciplina significava ensino, educação e, posteriormente, veio significar ensino, matéria ensinada. Estes dois significados acabaram se mantendo na Língua Portuguesa e ganharam os seguintes contornos: (1) disciplina enquanto poder - disciplina militar ou eu tenho problemas disciplinares com meus alunos; (2) saber - disciplina de Matemática, Psicologia, Literatura, outros.

Falar de Educação significa então falar de um campo de ações em que se relacionam 'poder' e 'saber'. Falar de educação escolarizada significaria então falar em uma instituição onde um sistema de ensino de uma ritualização da palavra se interconstituem em um sistema de poder e de saber, ou seja, um lugar desta difusão.

Este lugar nós aprendemos com Durkheim (1978) que é "lugar de criança", ou seja, "lugar de criança é na escola". Durkheim não foge a regra deste pressuposto cultural que descreve Foucault e outros. Ele é categórico ao nos ensinar que se há um problema, uma doença, uma "anomia social" ela se deve ao fato da "flexibilização do espírito de disciplina" do homem moderno. Esta flexibilização que levará o homem a ter sede de coisas novas, de alegrias desconhecidas, de sensações inconfessáveis é esta flexibilização que produz a paixão.

Esta estranha e voraz paixão de que fala Durkheim (1978) não tem lugar reservado no adulto, mas os pacientes desta doença terrível e avassaladora são as próprias crianças. São elas que devido à sua curiosidade, imaginação e instabilidade podem colocar em

Educ. e Filos., Uberlândia, v. 21, n. 41, p. 155-167, jan./jun. 2007. 
risco a construção da sociedade moderna. É neste ponto que Durkhein é taxativo quando diz que devemos nos curar desta doença e que precisamos nos ver livres deste mal que nos persegue e precisamos encontrar um remédio. Este remédio é então a Educação que, como coloca Fernandes (1997), passa a ser

[...] esse processo que só termina quando internamente encarnado, o outro se tornou nova instância psíquica da subjetividade, quando esta instância crítica e observadora do eu já está internamente atuante como mestre que se tornou obediente: o adulto normal (FERNANDES, 1997 p. 64).

A construção deste espírito de disciplina passará então por uma declaração de guerra contra as paixões, pelo espírito de abnegação e pela autonomia da vontade. Este pilar que é constituído pelo pai da sociologia é produto e produtor da noção de disciplina que Foucault (1999) descreveu, assim como também é o balizador das questões entorno da Educação e da Escola, ou seja, pensar o fenômeno educativo, bem como a instituição Escola nos coloca diante das questões do "saber e do poder", ou de um outro modo, do "aprender o saber" e do "poder ensinar".

Vemos-nos diante de uma curiosa situação, a da relação de poder/saber que se estabelece na Educação. A apropriação do "saber" garante ao sujeito o estatuto de "poder" sob o que "não sabe". Relações que por vezes se orientam em práticas 'emudecedoras', 'infantilizadoras', práticas pedagógicas que marcam e definem modos e meio e um aprendizado reprodutivista de uma verdade supostamente única, de uma educação tutelar e não emancipatória.

Este modelo de educação, que as idéias de Durkheim (1978) propõem e as de Foucault (1999) descrevem nos apresenta à uma lógica que abarca uma noção do que poderíamos chamar de uma "lógica da explicação" que é uma idéia que comporta um princípio de regressão ao infinito, diz Rancière (2003) no seu livro O Mestre Ignorante e continua dizendo que o problema é que o modo explicativo é sempre um modo de pensar, uma lógica do explicador, 
[...] o mito pedagógico, [...] divide o mundo em dois. Mas deve-se, dizer, mais precisamente, que ele divide a inteligência em duas. Há segundo ele uma inteligência inferior e uma inteligência superior. A primeira registra as percepções ao acaso, retém, interpreta e repete empiricamente, no estreito círculo dos hábitos e das necessidades. É a inteligência da criancinha e do homem do povo. A segunda conhece as coisas por suas razões, procede por métodos do simples ao complexo, da parte ao todo. É ela que permite ao mestre transmitir seus conhecimentos, adaptando-os às capacidades intelectuais dos alunos, e verificar se o aluno entendeu o que acabou de aprender. Tal é o principio da explicação [...] tal é o principio do embrutecimento (RANCIÈRE 2003, p. 24).

Este meu percurso procura romper com este modelo educativo, pois nele trabalha-se no campo do previsível, do já esperado, pois a Educação é vista como o processo no qual tiraremos a criança da condição daquele que "não é", para torná-la aquele que é, o ser pronto, acabado, educado. É neste tocante que verifico se manifestam boa parte dos processos de Formação Docente, tanto a inicial, nos cursos de graduação, como as continuadas, nas diferentes frentes de trabalho. Não questiono neste aspecto qual modelo de capacitação docente que se apresenta, se em cursos de pós-graduação, em cursos rápidos de atualização ou, ainda, em capacitação em serviço, o que pretendo questionar é o movimento, os contornos da idéia de educação e de infância que nele se apresentam. Se a capacitação é em serviço, em cursos, em programas de pós-graduação, parece já nos ter ensinado que pouco na prática concreta de sala de aula se altera, as práticas docentes continuam em um continum, o que busco é compreender de que modo nas práticas "pedagogicamente corretas ou não", refletem uma relação uma perspectiva educativa pouco ou nada emancipatória.

Enfim, muitos cursos com boas ou más intenções partem do mesmo princípio, o de que os professores são mal formados, mal

Educ. e Filos., Uberlândia, v. 21, n. 41, p. 155-167, jan./jun. 2007. 
orientados e por isso trabalham mal com as crianças, ensinam mal e pouco compreendem do processo de ensino e aprendizagem. Este princípio se pauta em uma lógica na qual doutores e intelectualizados, conhecedores de Piaget e Vigotski, pessoas que circulam por teorias que decifram o que e como fazer na e para escola podem ensinar, pode-se ensinar os professores e ou educadores mesmo sem saber nada sobre o lugar concreto da sala de aula em que o professor vive sua realidade. Neste percurso, o mais curioso é que os professores, mesmo que digam que teoria é uma coisa e prática é outra, gostam e se sentem geralmente iluminados pelos cursos de formação e capacitação docente.

Quero dizer com isso que há quase um pacto entre os (de)formadores e os (in)formados, de que estes últimos muito precisam saber, e os primeiros muito têm a ensinar, mesmo pacto descrito acima que também se estabelece entre o professor e o aluno, que é embrutecedor. Nesta relação, como já vimos, verificamos que há certa previsibilidade do fazer pedagógico, as faixas etárias estão estabelecidas e com isso as atitudes e comportamentos das crianças determinados, os conteúdos estão amarrados em uma cadeia disciplinar que marca hora e lugar de aprender. O professor se propõe a adequar seu discurso para os diferentes níveis intelectuais e sociais de seus alunos e assim infinitamente poderíamos descrever esta previsibilidade e demarcando os lugares seguros para a nossa prática.

Poderíamos nesta linha apontar que este mesmo percurso que se verifica, em um processo de formação das crianças observa-se na formação dos professores, um espelha o outro e assim os processos de produção e reprodução de especularidade comportam um espelhamento que tende ao infinito, e crianças (alunos) acabam sendo adultizadas e os adultos (professores) infantilizados.

O fato é que as queixas não param de aumentar e as dificuldades dos professores caminham de forma galopante ao topo do morro. Se nós podemos entender que professores estão em uma graduação mais atualizada e adequada, que os cursos de capacitação estão oferecendo mais recursos aos docentes, e outras coisas mais, podemos também perceber, um paradoxo neste 
aspecto. Afinal, se os professores estão melhores e mais aptos, por que as dificuldades têm aumentado? Por que temos a sensação de que a educação tem piorado?

Procurarei, sem a pretensão de dar qualquer solução às questões por hora apresentadas, caminhar por uma reflexão que nos coloque em espelho as soluções oferecidas pela escola. Para tanto recorrerei, em um primeiro momento, a outras linguagens que não as apresentadas freqüentemente nos discursos acadêmicos, mas buscarei no cinema e nas artes plásticas frestas para uma reflexão.

\section{Por não saber aonde ir}

O cinema vem se apresentando a nossa cultura como um espaço cultural que dialeticamente também é produto e produtor dos modos de vida em nossa sociedade. A forma bastante arrojada pela qual o cinema cria modos de vida, ideologias, atitudes, entre outros, pode ser atribuído pelo fascínio de nossa época pela imagem, mas também ao brilhantismo de muitos roteiristas ou diretores, pela leveza de alguns autores, pelo brilhantismo tecnológico ou, ainda, pela aproximação desta linguagem com nossa forma acelerada de viver, pois afinal é mais 'rápido' ver um filme baseado em uma obra literária do que ler esta obra.

Benjamin (1985, p. 187), faz uma análise relevante a respeito desta temática, dizendo que se por um lado a fotografia, o cinema e a imprensa jogaram a arte no lugar comum de todas as outras coisas, podemos considerar este movimento social "retrógrado diante de Picasso, mas se torna progressista diante de Chaplin". O cinema, na opinião do filósofo alemão, permite que se democratize produções que até antes de sua invenção era privilégio apenas da elite. A variedade de filmes e temas que hoje encontramos nas salas de cinema aumentam na mesma proporção que parece aumentar as pluralidades nos modos de viver de nossa cultura.

Verificamos no cinema um intenso intercâmbio entre a realidade e a ficção, relação que acaba produzindo narrativas, enredos em documentários, dando formatos de ficção (destacaria

Educ. e Filos., Uberlândia, v. 21, n. 41, p. 155-167, jan./jun. 2007. 
neste caso o documentário francês Ser e Ter) e em ficções com características de documentários (como na brilhante obra Dançando no Escuro). Este avanço nas direções, roteiros, atuação e tecnologia acabam, muitas vezes, quase que produzindo uma indistinção entre a vida e a arte, a tal ponto que não sabemos mais o que imita o que.

É assim que podemos perceber que não sabemos nunca ao certo a realidade dos fatos e os fatos da realidade, pois editados, formatados, nos deixam sem saber o que de fato aconteceu ou motivou as edições ou formatações. Ouvi, certa ocasião, que Rosselini fez Alemanha ano Zero por desejar muito filmar uma cena, uma única cena, a do garoto atravessando a ruína. Escrevo este texto em meados de novembro de 2005, na semana em que será lançado no Brasil o novo filme de Polanski, Oliver Twist, baseado na obra de mesmo nome de Charles Dickens. É importante deixar claro que não vi o filme, ou seja, falo de um filme que eu não assisti. Quero apenas falar de uma declaração do diretor em uma reportagem ao jornal Folha de S. Paulo, de 17 de novembro de 2005.

Polanski, segundo a reportagem, é um homem fascinado por detalhes e pela possibilidade de acontecimentos banais que podem mudar o rumo das vidas das pessoas. Falando de como foi fisgado pela obre, ele diz que no terceiro capítulo do livro há uma cena decisiva. O diretor descreve a cena:

O juiz vai assinar a sentença que acabaria com a vida de Oliver (o garoto seria entregue a exploração de um criminoso) sem nem olhar para ele, que está a sua frente chorando. Mas o tinteiro não está no lugar de sempre. Quando move o braço para o outro lado da mesa o juiz vê Oliver. E não assina a sentença. Só por que um tinteiro não está onde deveria.

Foi esta cena que capturou Polanski e que na entrevista do diretor também me capturou, fazendo-me estabelecer vinculação direta com o problema da educação. A construção desta interface entre educação e cinema não é algo dado a priori (aliás, criar 
indicativos para esta construção acaba sendo implicitamente um dos objetivos deste trabalho), mas é um produto narrativo ou "uma invenção", uma produção em que se tecem os fios e as tramas de um enredo. Neste movimento, o que verificamos é que algumas obras, alguns diálogos ou mesmo algumas cenas cinematográficas são de suma importância para criarmos alguns fios da tecitura da trama.

No referido filme de Polanski, creio que a argumentação do diretor já diz muito a nós, não entrarei no detalhe da cena, mas procurarei analisar um certo por menor da cena/entrevista, ele diz: "[...] o tinteiro não está no lugar de sempre. Quando move o braço para o outro lado da mesa o juiz vê Oliver. E não assina a sentença [...]" é aqui que me parece estar um dos temas enredos possível para pensar alguns temas relativos às questões da educação.

Estamos a todo tempo procurando, vasculhando, nas teorias e nas reflexões, aquilo que pode vir a ser previsível na Escola e na Educação. Estamos na tentativa de entender as causas e os efeitos de nossas práticas e de nossas posturas com as crianças, estamos procurando o tinteiro no lugar que ele sempre esteve, no lugar que aprendemos a procurá-lo sem saber e sem olhar o que estava a nossa frente, sem ver qual sentenças assinamos. Estamos sempre diante daquilo que está imediatamente à frente de nossos olhos, procuramos as coisas em seus lugares e quando ela não está nos assustamos. Mas também neste susto podemos salvar vidas, salvar histórias. O tinteiro fora do lugar representa as coisas fora do lugar, representa que se lidamos no campo do previsível podemos assinar sentenças sem nos contagiar com o choro de uma criança.

Muitas vezes é este o movimento presente nas escolas e nas práticas educativas, o problema que surge, emerge nesta linha é que, povoados com coisas fora do lugar nas escolas e sala de aula, não procuramos o tinteiro na mesa, e com isso não 'trombamos' com os olhares que estão na nossa frente, assim como não buscamos a soluções nas crianças e nos seus devires, mas sim em cursos distantes e desconectados de nossa realidade e em teorias que nos servem como uma roupa nova, uma camisa de força.

Do cinema vou a uma célebre frase de um dos mais importantes

Educ. e Filos., Uberlândia, v. 21, n. 41, p. 155-167, jan./jun. 2007. 
artistas plásticos do século XX, Pablo Picasso, ele é contundente quando diz "[...] aos doze anos, pintava como um adulto [...] e precisei de toda uma vida para pintar como uma criança". Se a entrevista de Polanski sugere que olhemos para outras e variadas possibilidades na busca de soluções e de sentenciamentos que fazemos cotidianamente, a fala de Picasso talvez nos acene para uma destas possibilidades de pensarmos a Educação e, com isso, a formação do professor, pois se há possibilidades elas podem estar exatamente no reverso daquilo que se apresenta, ou seja, não na lógica fechada e estruturada da razão adulta, mas na contraposição da não-lógica da não-razão da infância, expressa no choro de Oliver de Dickens e no desejo de Picasso.

Refletindo sobre isso é possível pensar que a imagem do homem colocada diante daquilo que está presente no prefixo in- da palavra infância nos remete a nossa falta originária de linguagem, de palavra e de razão. Ora a infância coloca-nos ao pé a revelação esclarecida por Aganbem (apud GAGNEBIN, 1997), de uma experiência inefável:

[...] não por ter um início paradisíaco além das palavras, ao mesmo tempo sem palavras, sem linguagem e, porém, condição de possibilidade de sua eclosão - que essa experiência exclui que a linguagem possa se apresentar como totalidade da verdade (p. 98-99).

Isso nos deixaria fora da condição confortável em que nos encontramos como adultos, pois a razão possui também sua completude e, assim, a linguagem nos traz a marca da infância, como origem, como incompletude.

Dessa forma, a infância nos revela duas faces de nossa constituição enquanto sujeitos: uma na qual vivemos a ilusão da completude na vida adulta e, a outra, que escancara essa incompletude explícita na própria infância.

Assim, a possibilidade de pensar uma Formação Docente se apresenta na sua impossibilidade, pois educar a infância deveria ser um processo intenso de nos deseducar, uma vez que pensar o 
ser da não razão é o modo de pensar a pluralidade do ser da razão. Olhar para os caminhos que se abrem na discussão das relações entre o adulto e a criança é pensar também no labirinto, a mais precisa e dispersa imagem da infância, pois ele,

Revela a estrutura misteriosa do desejo humano que não cessa com a obtenção de sua meta, mas se compraz em inventar desvios, imagens, gestos, palavras; ele é o outro lado da cultura, outro mas conjunto. A Infância Berlinense descreve esse avesso, [...] o avesso e o direito são inseparáveis como o 'lembrar' que forma a trama e o esquecimento que forma a urdidura no tecido do mesmo texto. [...]. O fio de Ariadne que guia a criança no labirinto não é somente o da intensidade do amor e do desejo; também é o fio da linguagem, às vezes entrecortado, às vezes rompido, o fio da história que nós narramos uns aos outros, a história que lembramos, também a que esquecemos e a que, tateante, enunciamos hoje (GAGNEBIN, 1994, p. 105).

\section{Referências}

BENJAMIN, W. Reflexões: a criança, o brinquedo, a educação. São Paulo: Summus, 1985.

COSTELLO e MÁRCICO. Glossário etimológico de términos usuales em la práxis docente. In: KOHAN, W. Infância e Filosofia. Belo Horizonte: Autêntica Editora, 2002.

DURKHEIM, E. Educação e Sociologia. Rio de Janeiro: Melhoramentos, 1978.

FERNANDEZ, H. Infância e modernidade: doença do olhar. In: GUIRALDELLI JR., P. (Org.). Infância, escola e modernidade. São Paulo: Cortez, 1997.

FOUCAULT, M. A ordem do discurso. São Paulo: Loyola. 1999. 
GAGNEBIN, J. M. História e narração em W. Benjamin. São Paulo: Perspectiva, 1994.

. Infância e pensamento. In: GUIRALDELLI JR., P. Infância, escola e modernidade. São Paulo: Cortez, 1997.

LEITE, C. D. P. Labirinto: infância, linguagem e escola. 160 f. 2002. Tese (Doutorado em Educação) - Faculdade de Educação, Unicamp, Campinas, 2002.

PIAGET, J. Seis estudos de Psicologia. Tradução de Maria Alice Magalhães Damorim e Paulo Sérgio Lima Silva. 17. ed. Rio de Janeiro: Forense Universitária, 1989.

RANCIÈRE, J. O mestre ignorante. Belo Horizonte: Autêntica Editora, 2004.

VIGOTSKI, L. S. Teoria e Método em Psicologia. São Paulo: Martins Fontes, 1999.

VYGOTSKY, L. S. Pensamento e linguagem. 2. ed. São Paulo: Martins Fontes, 1989b.

VYGOTSKY, L. S. A formação social da mente. 3. ed. São Paulo: Martins Fontes, 1989a. 